\title{
LOPO FERNANDES PACHECO: UM VALIDO DE D. AFONSO IV*
}

\author{
Vanda LOURENÇO
}

\begin{abstract}
RESUMEN: El túmulo de Lopo Fernandes Pacheco se ha estudiado abundantemente por varios autores. No obstante, poco se sabe sobre este señor que ocupó una posición muy destacada en la corte del rey D. Alfonso IV (1325-1357). No olvidando los estudios ya realizados sobre el túmulo este trabajo se ocupará de trazar el recorrido vital de este valido regio, demostrando que la grandeza de su monumento funerario, localizado en la capilla de S. Cosme y S. Damián en la cabecera de la catedral de Lisboa, puede ser un buen reflejo de la importancia de este personaje que según el Livro de Linhagens do conde D. Pedro, fue hecho noble por don Alfonso IV.
\end{abstract}

PALABRAS CLAVE: nobleza, Portugal, siglo XIV, Lopo Fernandes Pacheco. linaje, corte, patrimonio.

ABSTRACT: The Lopo Fernandes Pacheco gothic tomb, located inside Lisbon's Cathedral in S. Cosme e S. Damião Chapel, has been attracted the attention of many authors. Nevertheless few things are known about this man, who fills a prominence position in the D. Afonso IV royal's court (1325-1357). The present work looks to draw the course followed by this royal vassal without neglecting the studies dedicated to the tomb itself. The magnificence of this funerary monument reveals the importance of this man made lord by D. Afonso IV as said in the Livro de Linhagens do Conde D. Pedro book.

KEYWORDS: noblesse, Portugal, XIV century, Lopo Fernandes Pacheco, lineage, court, property.

Este trabalho que agora publicamos ${ }^{1}$ procura dar a conhecer um pouco mais do percurso de Lopo Fernandes Pacheco, de quem muito se escreve sobre o seu belo túmulo localizado na capela de S. Cosme e S. Damião na Charola da Sé de Lisboa ${ }^{2}$, mas que muito pouco se tem escrito sobre o seu património, a composição dos seus servidores e criados ...

* Bolseira de Doutoramento da Fundação para a Ciência e Tecnologia.

${ }^{1}$ Este texto foi apresentado numa comunicação proferida no II Seminário Aberto do Instituto de Estudos Medievais - Faculdade de Ciências Sociais e Humanas - Universidade Nova de Lisboa, em Junho de 2005.

${ }^{2}$ Sobre os estudos relativos ao túmulo de Lopo Fernandes Pachecos veja nota infra n. ${ }^{\circ} 68$. 
O Livro de Linhagens do Conde D. Pedro tem título autónomo para os Pachecos que "descenderom" de "Fernam Jeremias". Este cavaleiro que acompanhou o conde D. Henrique recebeu de D. Teresa o senhorio de Ferreira de Aves ${ }^{4}$. Apesar dos seus descendentes terem estabelecido uma ligação aos sucessivos monarcas portugueses não conseguiram alcançar uma posição relevante na corte, talvez, por isso, as suas informações são muito escassas. É, assim, necessário esperar pelo quinto senhor de Ferreira, Fernão Rodrigues, avô de Lopo Fernandes, para os dados sobre esta linhagem serem mais abundantes. De salientar, que Fernão Rodrigues foi o primeiro membro da estirpe a utilizar o apelido Pacheco ${ }^{5}$. Devido à importância que alguns dos seus membros alcançaram, dos quais se destaca Lopo Fernandes, esta linhagem inicia a sua trajectória ascensional somente no século $\mathrm{XIV}^{6}$. Porém, devido a uma série de peripécias terminará a sua ascensão em Castela ${ }^{7}$. Muito terá contribuído para este engrandecimento o vazio social provocado pelo desaparecimento das velhas linhagens, ocorrido durante o reinado de D. Dinis, que permitiu a irrupção de novas estirpes ${ }^{8}$. Assiste-se, assim,

${ }^{3}$ Livro de Linhagens do conde D. Pedro, ed. J. Mattoso, 2 vols., Lisboa, 1980, Título 50 (doravante citado como $L L$ ).

4 A. Franco Silva, e J. A. Garcia Lujan, "Los Pacheco. La imagen mítica de un linaje português en tierras de castilla", Actas das II Jornadas luso-espanholas de Historia Medieval, vol. III, Porto, 1989, pp.954-955.

${ }^{5}$ Leontina Ventura afirma que "foi desde que se estabeleceu numa terra (...), de que passou a trazer o nome, e adoptou um esquema sucessório unilinear masculino (...) que a família tomou consciência de si e da sua coerência. (...) O espaço estruturou a família, que passou a designar-se pelo nome desse espaço. (...) À apropriação do nome seguiu-se a identificação com o espaço" (L. VenturA, "Terras e julgados", Nova História de Portugal, dir. de J. Serrão, e A. H. de O. MARQueS, vol. III - Portugal em definição de fronteiras (1096-1325). Do condado portucalense à crise do século XIV, coord. por M. H. da C. Coelho e A. L. de C. Homem, Lisboa, 1996, pp. 547. IDEM, A nobreza de corte de Afonso III, vol. I, Coimbra, 1992 (dissertação de Doutoramento policopiada), pp. 306-312; J. MATTOSO, Identificação de um país. Ensaio sobre as origens de Portugal. 1096-1325. vol. I - Oposição, Lisboa, 2001, p. 131).

${ }^{6}$ R. C. Gomes, A corte dos reis de Portugal no final da Idade Média, Lisboa, 1995, p.72.

7 "Controlará durante cerca de cuarenta años la vida política de ese reino y, al amparo de su privanza, de su poder, creará un vasto conjunto teritorial que la convertiría en uno de los más ricos linajes de la Península Ibérica" (A. Franco Silva, e J. A. Garcia Lujan, "Los Pacheco (...)”, pp. 943-944).

8 J. A. Pizarro, Relações político nobiliárquicas entre Portugal e Castela: o Tratado de Escalona (1328) ou dos "80 fidalgos", sep. da Revista da Faculdade de Letras - História, II série, vol. XV Porto, 1998, pp. 1255-1277; IDEM, Linhagens medievais portuguesas. Genealogias e estratégias (1279-1325), 3 vols., Porto, 1999; Salvador de Moxó, "De la nobleza vieja a la nobleza 
durante a centúria de Trezentos a um importante processo de substituição das velhas famílias por linhagens de uma nobreza inferior. É neste título 50 do Livro de Linhagens que vamos encontrar referências a Lopo Fernandes ${ }^{9}$. No entanto, essas menções são muito escassas podemos, somente, estabelecer uma sucessão genealógica [Esquema Genealógico I]. No entanto, o título dos Pachecos termina referindo que Lopo Fernandes foi "ricomem e muito honrado, e feze-o el rei dom Afonso, o quarto"10.

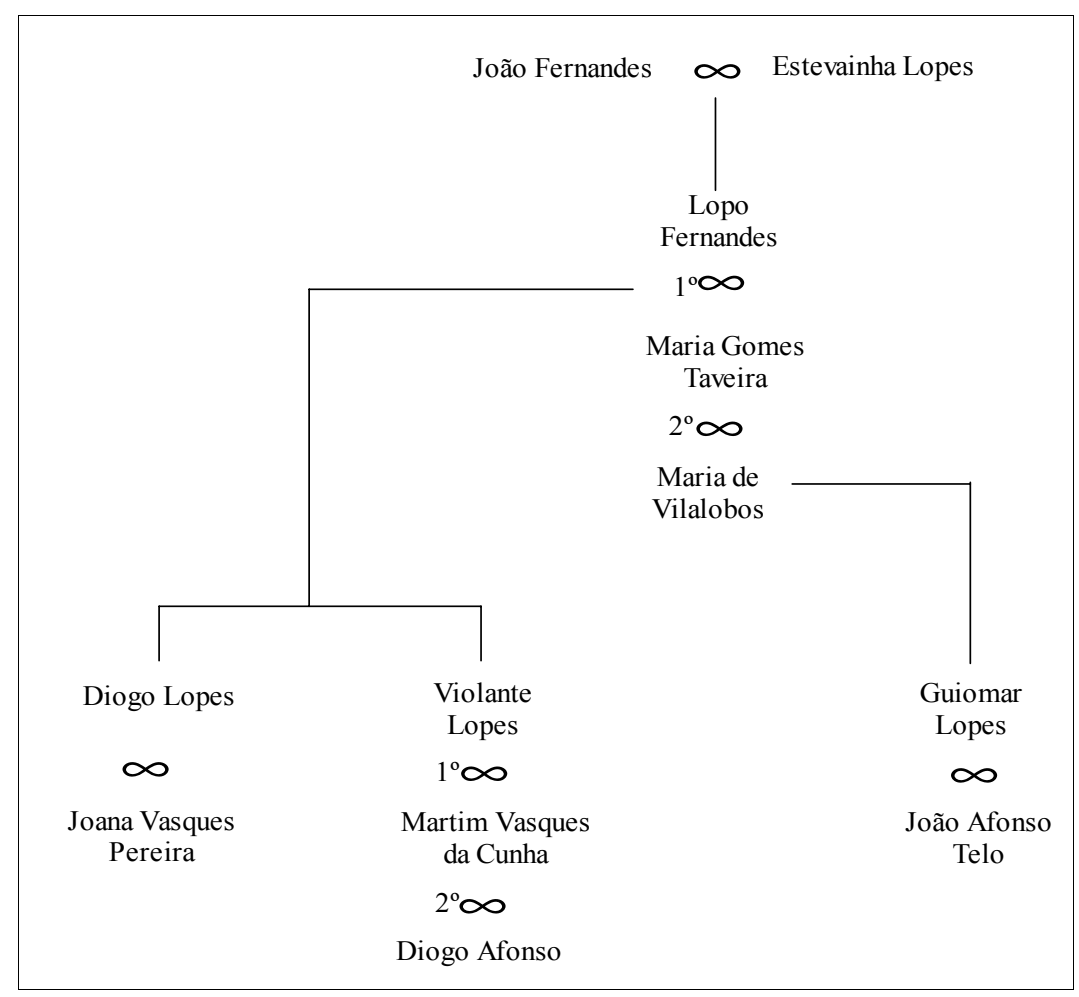

Esquema Genealógico I - Inserção de Lopo Fernandes Pacheco (segundo o LL)

nueva. La transformación nobiliária castellana en la Baja Edad Media”, Feudalismo, señorio y nobleza en la Castilla medieval, Madrid, 2000, pp. 311-370.

${ }^{9}$ LL 50A6-7.

${ }^{10}$ LL 50C7. 
Vejamos, então, quem foi este rico-homem. Lopo Fernandes, sétimo senhor de Ferreira, era filho de João Fernandes Pacheco, sexto senhor de Ferreira, e de Estevaínha Lopes de Paiva ${ }^{11}$. Seu pai frequentou os círculos de D. Dinis, porém uma figura de pouco relevo ${ }^{12}$. Em 1327 Lopo Fernandes teria já contraído o seu primeiro matrimónio com D. Maria Gomes Taveira ${ }^{13}$, do qual nasceram Diogo Lopes Pacheco e Violante Lopes. No ano de 1345 encontrava-se casado com sua segunda mulher, D. Maria de Vilalobos ${ }^{14}$, neta, por parte da mãe, do rei D. Sancho IV, de Castela, avô do rei D. Afonso, XI de Castela. Deste casamento nasceu Guiomar Lopes Pacheco que casou com João Afonso Telo, $4^{\circ}$ Conde de Barcelos ${ }^{15}$ [Esquema Genealógico I].

Segundo José Mattoso durante o período da guerra civil de 1319-1324 que opusera o infante D. Afonso a seu pai, o rei D. Dinis (1279-1325), os Pachecos pertenceram ao grupo de alguns membros da nobreza que preferiram manter a neutralidade durante o conflito esperando, assim, os resultados sem querer intervir $^{16}$. No entanto, consideramos que, desde muito cedo, a presença de Lopo Fernandes junto dos círculos régios é bastante assídua. Por um lado, confirma o testamento da rainha $\mathrm{D}$. Isabel redigido em Coimbra no ano de $1327^{17}$ e, por outro, durante o reinado de D. Afonso IV (1325-1357) foi agraciado com os seguintes cargos: meirinho-mor ${ }^{18}$, mordomo-mor do infante D. Pedro, herdeiro do trono ${ }^{19}$, pertenceu ao conselho do rei ${ }^{20}$ e foi nomeado pelo Bravo como seu Embaixador nas Corte papal, de Castela e de Aragão onde foi, muitas vezes, a serviço do monarca

${ }^{11}$ LL 50A6-7. Gostaríamos de referir que as fontes utilizadas são as já arroladas para um outro trabalho de maior fôlego que estamos a preparar. Muitas das afirmações feitas serão, por isso, meras hipóteses que poderão, ou não, vir a ser confirmadas com a muita documentação que nos falta ainda indagar.

12 A. Franco Silva, e J. A. Garcia Lujan, "Los Pacheco (...)”, p.958.

${ }^{13}$ IAN/TT, Mosteiro de Santa Maria de Alcobaça, $2^{\mathrm{a}}$ inc., m.11, n. ${ }^{\circ} 251$.

${ }^{14}$ IAN/TT, Mosteiro de Santa Cruz de Coimbra, 2ainc., m.48, Alm.34, m.9, n. ${ }^{\circ} 28$.

${ }^{15}$ LL $50 \mathrm{C} 7$.

${ }^{16}$ Sobre esta conjuntura veja-se J. MATTOSO, “A guerra civil de 1319-1324”, Obras Completas, vol. 8, Lisboa, 2002, pp. 217-227.

17 A. de Vasconcelos, Dona Isabel de Aragão (a rainha Santa), vol. II, ed. fac-similada, Maia, 1993, p. 17

${ }^{18}$ IAN/TT, Mosteiro de Santa Maria de Alcobaça, $2^{\mathrm{a}}{ }^{\mathrm{inn}} ., \mathrm{m} .11$, n. ${ }^{\circ} 251$; Gav.21, m.10, n. ${ }^{\circ} 15$.

${ }^{19}$ IAN/TT, Mosteiro de Santa Cruz de Coimbra, $2^{\mathrm{a} i n c} .$, m.17, n. ${ }^{\circ} 10$.

${ }^{20}$ IAN/TT, Gav.18, m.5, n. ${ }^{3} 32$; As Gavetas da Torre do Tombo, vol.8, p.566-575. 
${ }^{21}$. Consideramos, assim, que estes dois factores são reveladores da privança que, desde muito cedo, Lopo Fernandes manteve com D. Afonso, ainda príncipe herdeiro, e que durante a guerra civil de 1319-1324 não deve ter tomado uma posição neutra, mas sim, de apoio às pretensões do jovem infante. Um outro exemplo de sua grande proximidade é-nos revelado na lista dos 40 nobres indicados como reféns por D. Afonso IV no tratado de ratificação de 1328 celerado com o rei D. Afonso XI de Castela, através do qual estes dois monarcas confirmaram o tratado de Agreda (1304), anteriormente estabelecido entre D. Dinis e D. Fernando IV, seus respectivos pais ${ }^{22}$. Neste documento, D. Afonso IV nomeou um grupo de fidalgos da sua máxima confiança para responderem pela alcaidaria dos castelos envolvidos no acordo diplomático, surgindo à cabeça dessa lista o nome de Lopo Fernandes Pacheco, seguido por alguns membros das mais prestigiadas linhagens do reino. Demonstração máxima da confiança que o monarca tinha neste seu vassalo é revelada na criação dos infantes D. Pedro e D. Leonor $^{23}$. Foi, também, um dos cavaleiros que acompanhou o Bravo e o ajudaram a vencer a batalha do Salado ${ }^{24}$. Revelador de todo o prestígio e importância alcançados por este senhor é a oferta de uma rosa de ouro pelo Papa Bento XII aquando de uma visita à cúria pontifícia ${ }^{25}$.

${ }^{21}$ IAN/TT, Gav.18, m.5, n. ${ }^{\circ} 32$; As Gavetas da Torre do Tombo, vol.8, p.566-575; ADF, Caja 1, n. ${ }^{\circ} 1$, tranc. por A. Franco Silva, "Los Pacheco (...)”, p.977-979.

${ }^{22}$ Sobre este tratado veja-se J. A. PIZARro, Relações político nobiliárquicas (...), pp. 1255-1277; B. V. e SousA, As relações entre Afonso IV de Portugal e Afonso XI de Castela. O contrato de confirmação de 1328, draft, assim como a bibliografia citada por estes dois autores.

${ }^{23}$ ADF, Caja 1. n. ${ }^{\circ}$, tranc. por A. FrANCO SiLVA, "Los Pacheco (...)”, p.977-979.

${ }^{24}$ M. BARRoCA, Epigrafia medieval portuguesa (862-1422), vol. 2/T. II, Lisboa, 2000, p.1699. Sobre a batalha do Salado veja-se, B. V. e SousA, "Vencer ou morrer. A batalha do Salado", Actas do Colóquio A memória da Nação, Lisboa, 1987, pp. 505-514; IDEM, "O sangue, a cruz e a coroa - a memória do Salado em Portugal", Penélope, 2, 1989, pp.28-48, assim como a bibliografia citada por este autor; J. G. MonTEIRO, "As campanhas que fizeram a história", Nova história militar de Portugal, dir. de M. T. BARATA, e N. S. TeIXeIRA, vol. I, pp. 248-249;

${ }^{25}$ Lopo Fernandes Pacheco foi o primeiro português a ser distinguido com este presente papal. Até à primeira metade do século XV só $\mathrm{D}$. Afonso $\mathrm{V}$ foi distinguido com igual gesto de um Papa. “ $A$ Rosa de Ouro era uma rosa que era benzida e consagrada pelo Papa no $4^{\circ}$ Domingo da Quaresma, $e$ que se documenta desde os meados do século XII. Era hábito o Papa entregar a Rosa de Ouro a uma pessoa que pretendesse distinguir e dignificar. (...). Em Portugal e de acordo com o estudo de Francisco Marques Sousa Viterbo, foram distinguidos com igual gesto [para além dos já referidos] $D$. Manuel (em 1506 e em 1514), D. João III (em 1525), e as Rainhas D. Catarina, D. Maria II e D. Amélia (esta em 1892)" (in M. BARrocA, Epigrafia medieval (...), vol. 2/T. II, p.1709, nota n. ${ }^{\circ 302}$ ). Veja-se também, F. M. S. Viterbo, "A rosa de ouro. Presentes a D. João III, à igreja de Santo António e a Lopo Fernandes Pacheco. Um túmulo monumental na Sé de Lisboa", Curiosidades históricas e artísticas, Coimbra, 1919, pp.20-30; M. de TÁvorA, "A heráldica medieval na Sé de 
Além de todas estas funções que ocupava na corte régia Lopo Fernandes não podia descurar as obrigações para com os seus parentes mais chegados. Assim, D. Afonso IV nomeou-o tutor de seus netos Vasco, Leonor e Inês ${ }^{26}$. No entanto, os cargos na corte régia, bem como a administração da sua vasta mancha patrimonial, deviam manter o senhor de Ferreira muito ocupado. Assim, porque não podia administrar como cumpria os bens de seu neto, Vasco Martins, filho de Violante Lopes e Martim Vasques da Cunha ${ }^{27}$, nomeou Lourenço Martins Buval como tutor de seu neto ${ }^{28}$. A privança deste senhor com o monarca permitiu-lhe exercer cargos militares, administrativos e cortesãos, ao mesmo tempo que ocupava a mais alta posição na hierarquia da sociedade medieval. Todos estes aspectos conjugados constituem as causas do seu prestígio e de uma crescente fortuna familiar.

Podemos, deste modo, afirmar que a sólida fortuna económica e fundiária e, ainda, a força e importância politica permitiram a Lopo Fernandes deter uma proeminente posição no conjunto da nobreza do reino. De salientar, que a participação no Conselho régio, mais do que um ofício era reveladora de uma dignidade a que correspondia um determinado estatuto e um dado rendimento ${ }^{29}$. Lopo Fernandes tornou-se, assim, num elemento dinâmico e poderoso da nobreza que, talvez de uma maneira directa, influenciou a orientação política do Reino. Porém, a todo este prestígio será necessário acrescentar uma riqueza material que este senhor possuía e da qual alguns membros da família real se serviram em momentos de necessidade. Deste modo, Lopo Fernandes emprestou à rainha D. Maria, mulher do infante D. Pedro de Castela, para seu mantimento, a elevada quantia de duzentas dobras de ouro ${ }^{30}$. Encontramos, também, o sétimo senhor de Ferreira a frequentar os círculos das sucessivas rainhas. Assim, para além, de confirmar o testamento da rainha D. Isabel, como já referimos foi mordomo-mor $\left(1334-1336^{31}\right)$ e chanceler $\left(1349^{32}\right)$ da rainha D. Beatriz. Podemos, deste modo,

Lisboa", Boletim cultural da Assembleia Distrital de Lisboa, $3^{\text {a }}$ série, T.I, 1982, p. 161-170; M. BARROCA, Epigrafia medieval (...), vol. 2/T.II, p.1699.

\footnotetext{
${ }^{26}$ IAN/TT, OC, Mosteiro de Santa Maria de Lorvão, g.6, m.3, n. ${ }^{\circ} 7 / 2$.

${ }^{27}$ LL 50B8.

${ }^{28}$ IAN/TT, OC, Mosteiro de Santa Maria de Lorvão, g.6, m.3, n. ${ }^{\circ} 7 / 2$.

29 M. CAetano História do direito português. Fontes - direito público (1140-1495), $3^{\text {a }}$ ed., Lisboa, 1992, p.482; A. L. de C. HomEM, "Conselho Real ou conselheiros do rei? A propósito dos 'privados' de D. João I', Portugal nos finais da Idade Média: estado, instituições, sociedade política, Lisboa, 1990, p.16.

${ }^{30}$ IAN/TT, OSB, Mosteiro de Santa Maria de Aguiar, m.1, n. ${ }^{\circ} 11$.

31 IAN/TT, Mosteiro de Santos o Novo, m.42, n. ${ }^{8} 861$; Mosteiro de Chelas, m.41, n. ${ }^{9} 914$. , respectivamente.
} 
afirmar que a ligação deste senhor à corte régia demonstra, claramente, uma grande aproximação e confiança não só do monarca, mas também das rainhas.

Como já referimos, a ascensão dos Pachecos iniciou-se, principalmente, no século XIV devido à proeminência alcançada por Lopo Fernandes. Oriundo de uma nobreza de província este senhor ascende na hierarquia nobiliárquica tornando-se, talvez, na mais importante personagem do reinado do Bravo. Pertencendo à corte régia, este senhor possuía a sua própria "entourage" ${ }^{33}$. Em regra, a corte que acompanhava os senhores é de difícil reconstituição, talvez, porque os seus elementos se renovavam constantemente (por mudança de idade, de estatuto social, por morte, por desagrado do senhor e por muitos outros motivos). Porém, não raras vezes e, conjugando os dados dispersos é possível reconstituir alguns desses servidores e os cargos que desempenhavam. No entanto, a exiguidade dos dados disponíveis referem-se, somente, a uma parte dos seus dependentes que surgem especificados como simples escudeiros ou criados ... [Quadro I]. Sabemos que a corte senhorial era formada, essencialmente, pelos seus servidores privados, mas também por colaboradores laicos e religiosos que se constituíam como uma comunidade social que vivia em permanência com o senhor. Lopo Fernandes seria, assim, rodeado por um número não desprezível de homens que se encontravam ligados a si por laços de dependência pessoal. Entre aqueles que com ele conviviam diariamente não devemos esquecer os indivíduos que o senhor de Ferreira acolhera em criança, criando-os na sua companhia como membros da sua família e seus dependentes ${ }^{34}$. Podemos, também, entrever a organização de um serviço de

${ }^{32}$ IAN/TT, Mosteiro de Santa Cruz de Coimbra, $2^{\mathrm{a} i n c .,}$ m.17, n. ${ }^{\circ} 10$.

${ }^{33}$ Sobre as cortes senhoriais, veja-se M. C. A. e CunHA, e M. C. G. PIMENTA, "A casa senhorial do infante D. Henrique: organização social e distribuição regional", Revista da Faculdade de Letras História, 2a série, 1, Porto, 1984, pp.221-284; A. H. de O. MARQUES, "A nobreza", Nova História de Portugal, dir. de J. SERRÃo e A. H. de O. MARQUES, vol. IV - Portugal na crise dos séculos XIV e $X V$, Lisboa, 1987, pp. 257-260; J. MARQUES, A arquidiocese de Braga no século XV, Lisboa, 1988, pp.169-226; M. H. da C. Coelho, O baixo Mondego nos finais da Idade Média, vol. I, Lisboa, 1989, pp.565-569; I. Beceiro Pita e R. Córdoba De La Llave, Parentesco, poder y mentalidad. La nobleza castellana (siglos XII-XV); Madrid, 1990, pp.331-345; I. de SouSA, Introdução ao estudo do património, da casa e da corte de D. Leonor, sep. da Revista da Faculdade de Letras - Línguas e Literatura, anexo V - Espiritualidade e corte em Portugal, séculos XVI-XVIII, Porto, 1993, pp.23-52; L.F. Oliveira, A casa dos Coutinhos. Linhagem, espaço e poder (1360-1452), Cascais, 1999; J. L. FonTES, “A casa senhorial do Infante D. Fernando", Media Aetas. Revista de Estudos Medievais, 3/4, Ponta Delgada, 2000/2001, pp.103-139.

${ }^{34}$ Foram seus criados: Gonçalo Anes (IAN/TT, Mosteiro de Santa Ana de Coimbra, cx.1, m. 2, n. ${ }^{\circ} 11$, Mosteiro de Chelas, m.18, n. ${ }^{\circ} 347$ ); João Afonso (IAN/TT, OC, Mosteiro de Santa Maria de Lorvão, g.6, m.1, n. ${ }^{\circ} 12 / 1$ ); Lopo Esteves (IAN/TT, Mosteiro de Santos-o-Novo, m.66, n. ${ }^{\circ} 1331$ ); Pedro Anes (IAN/TT, Mosteiro de Santa Ana de Coimbra, cx.2, n. ${ }^{\circ}$ ); Pedro Rodrigues (IAN/TT, 
chancelaria que nos é sugerido pela existência do escrivão Estêvão Anes ${ }^{35}$. Numa esfera ainda mais próxima do senhor de Ferreira encontramos os servidores privados relativamente aos quais registamos a menção a cinco clérigos que asseguravam a vida espiritual ${ }^{36}$, bem como a um camareiro, Gil Martins ${ }^{37}$. Este último ocupava um dos cargos mais relevantes ligados à vida pessoal. Ao lado das funções de índole mais doméstica documenta-se, também, uma ocupação relacionada com a administração da justiça através do ouvidor Vicente Anes que estaria encarregue de ouvir as demandas nas terras que se encontravam na posse de Lopo Fernandes ${ }^{38}$. Como já referimos, Lopo Fernandes participou ao lado do rei na Batalha do Salado. Senhor de lides guerreiras tinha, também ele, ao seu serviço um número de escudeiros que deve ter sido muito superior àquele que as esporádicas referências documentais nos deixam entrever [Quadro I]. Com certeza esse quantitativo seria suficiente para assegurar o número de lanças com que o referido senhor estava obrigado a servir o rei. Estes escudeiros encontravam-se, também, incumbidos da guarda pessoal de Lopo Fernandes, assim como da defesa da sua casa e bens ${ }^{39}$. A disposição de um corpo de escudeiros era sinal de prestígio social e, não será demais repetir, que o senhor de Ferreira seria, na sua época uma das principais personalidades do reino, se não mesmo a principal. Não é raro que os escudeiros fossem encarregues de outras funções que dependiam da confiança do seu senhor. Deste grupo, apenas, Rui Vicente é referido como vassalo de Lopo Fernandes $^{40}$. De um modo geral, estes servidores não desempenhavam diferentes funções, ou seja, o que ressalta é uma ausência de polivalência dos variados ofícios em que as tarefas são muito precisas, o que nos poderá levar a supor, por um lado, que a corte senhorial de Lopo Fernandes era maior do que nos deixa entrever a documentação e, por outro, seria já ela o prelúdio de uma especialização das

Cabido da Sé de Coimbra, $2^{\mathrm{a}}$ inc, m.25, n. ${ }^{\circ} 1069$ e m.29, n. $\left.{ }^{\circ} 1222\right)$. Sobre a terminologia do termo criado veja-se, R. C. Gomes, A corte dos reis (...), cap. III, assim como a bibliografia aí citada por esta autora.

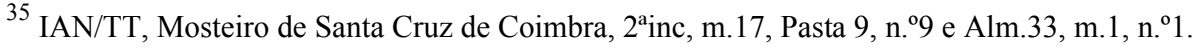

${ }^{36}$ IAN/TT, Gav.18, m.5, n. 32; G.T.T., vol.8, p.566-575; Mosteiro de Santos-o-Novo, m.42, n. ${ }^{\circ} 861$ e m.77, n. ${ }^{\circ} 1542$; Mosteiro de Santa Cruz de Coimbra, $2^{\mathrm{a}}{ }^{\mathrm{a}} \mathrm{nc}, \mathrm{m} .17$, n. ${ }^{\circ} 7$ e m.48, Alm.34, m.9, n. ${ }^{\circ} 16$.

${ }^{37}$ IAN/TT, Mosteiro de Santa Cruz de Coimbra, 2ainc, m.17, Pasta 9, n. ${ }^{\circ} 9$ e Alm.33, m.1, n. ${ }^{\circ} 1$.

${ }^{38}$ IAN/TT, Mosteiro de Santa Cruz de Coimbra, $2^{\mathrm{a}}$ inc, m.48, Alm.34, m.9, n. ${ }^{\circ} 27$. Sobre o ouvidor veja-se A. L. de C. Homem, O desembargo régio (1320-1433), Porto, 1990, pp. 141-144, assim como a bibliografia aí citada por este autor.

${ }^{39}$ IAN/TT, OC, Mosteiro de Santa Maria de Lorvão, g.5, m.5, n. ${ }^{\circ} 12 / 1$; IAN/TT, Mosteiro de Santos-o-Novo, m.42, n. ${ }^{\circ} 861$; IAN/TT, Mosteiro de Chelas, m.36, n. ${ }^{\circ} 702$.

${ }^{40}$ IAN/TT, Mosteiro de Chelas, m.36, n. ${ }^{\circ} 702$. 
funções que se começam a definir nas casas senhoriais. Estamos, assim, perante um vassalo régio que tinha o seu próprio grupo de vassalos perfeitamente documentados ${ }^{41}$. No entanto, desconhecemos os dados relativos à proveniência de cada um destes indivíduos ${ }^{42}$, assim como, tempo durante o qual serviram Lopo Fernandes. Estabeleceu-se, deste modo, uma rede de relações sociais, expressa num conjunto de servidores e serviços que se apresentava como uma família capaz de propiciar criação, educação e socialização. Assim, em torno do Senhor de Ferreira gravitava uma numerosa "criadagem" que dele recebia favores e rendimento. Aqui concentravam-se formas específicas de comportamentos sociais que transformavam a corte num veículo de identidade social.

De todo este poder não podemos dissociar o vasto conjunto de bens que Lopo Fernandes detinha. Segundo José Mattoso, a partir do século XIV assiste-se à instalação de grandes solares na zona da Beira e Estremadura, levando, deste modo, a uma movimentação das famílias nobres para o Sul, ou seja, para as regiões onde predominava o regime municipa ${ }^{43}$. Esta deslocação das novas linhagens pode ser entendida como uma tentativa de procurar fortuna em terras mais despovoadas. Uma primeira observação à mancha patrimonial detida por Lopo Fernandes [Mapa I] revela-nos, por um lado, uma mobilidade reduzida e, por outro, demonstra que este senhor preferiu dirigir os seus interesses para uma zona delimitada, ou seja, o curso do Rio Tejo, principalmente, na rica região agrícola de Santarém e seu termo, mas também na zona de Lisboa e seu termo. Para a escolha deste espaço muito terá contribuído a movimentação das famílias nobres para o sul do país, como já referimos, mas também, a ligação que Lopo Fernandes mantinha com a corte régia. Não podemos esquecer que a cidade escalabitana era, muitas vezes, local de longas estadas dos monarcas ${ }^{44}$, mas também, acessível a Lisboa por via fluvial, e, não menos importante, com uma posição geográfica central numa rica região agrícola,

${ }^{41}$ IAN/TT, Mosteiro de Santa Cruz de Coimbra, $2^{\mathrm{a} i n c, ~ m .17, ~ n . ~}{ }^{\circ} 10$. Foram eles Martim Lourenço (IAN/TT, Mosteiro de Santa Cruz de Coimbra, $2^{\mathrm{a}}$ inc, m.17, n. ${ }^{\circ}$ 10) e Rui Vicente (IAN/TT, Mosteiro de Chelas, m.36, n. ${ }^{\circ} 702$ ).

${ }^{42}$ Em apenas três deles nos é indicada a sua origem geográfica: Estêvão Gomes, prior de la Mota, Pedro de Lisboa, Afonso Esteves, que mora em Tomar (IAN/TT, Gav.18, m.5, n. ${ }^{0} 32$; Mosteiro de Santos-o-Novo, m.77, n. ${ }^{\circ} 1542$; Mosteiro de Santa Cruz de Coimbra, $2^{2}$ inc, m.17, Alm.33, m.1, n. ${ }^{\circ}$, respectivamente).

43 J. Mattoso, "A nobreza de Entre-Douro-e-Minho na história medieval de Portugal”, Papel das áreas regionais na formação histórica de Portugal. Actas do colóquio, Lisboa, 1975, pp. 47 e 60.

${ }^{44}$ Como já demonstrou Rita Costa Gomes, Santarém foi a segunda cidade onde as estadas dos reis com a sua corte revelou uma maior permanência, que não pode ser dissociada da distribuição sazonal (A corte dos reis (...), pp.251-254) 
ou seja, partindo de Santarém o monarca encontrava-se numa posição central no território do Reino. Como já o demonstrou Rita Costa Gomes, Santarém era " $a$ segunda localidade mais importante dos itinerários régios a curta distância de Lisboa, quer quanto ao número de visitas, quer na duração das estadas" ${ }^{45}$.

Não obstante a grande mancha patrimonial se localizar no centro-sul do país, encontramos bens situados em Ferreira de Aves, de onde era natural. É nesta zona que se localiza a única doação régia concedida a Lopo Fernandes sob a forma de morgado. O rei doou este senhorio pelos muitos serviços que recebeu de Lopo Fernandes Pacheco e de sua mulher, mas também pela criação dos infantes D. Pedro e D. Leonor, seus filhos, e, por outro lado, pelas embaixadas às Cortes de Roma, de Castela e de Aragão, onde o senhor de Ferreira foi, repetidas vezes, em serviço régio. Nestes domínios exercia Lopo Fernandes os seus direitos senhoriais e de jurisdição de mero e misto império, sendo a última apelação efectuada para o $\mathrm{rei}^{46}$. Esta concessão do monarca fortaleceu e prestigiou ainda mais este senhor.

Apesar das cidades se tornarem, a partir de meados do século XIII, em centros de decisão da economia e da política dos reinos, a sua população nobre não era muito numerosa. Porém encontramos alguns exemplos de membros da aristocracia a possuir bens em urbes ${ }^{47}$. Por regra, a maior parte dos indivíduos da nobreza detinha os seus bens de raiz fora das cidades, não impedindo que também os pudessem deter no interior das mesmas. Oriundo de uma nobreza de província Lopo Fernandes ascendeu socialmente devido à privança que estabeleceu com D. Afonso IV. Desta não deve ser dissociada a escolha geográfica para a detenção dos seus bens. Através de uma análise ao Mapa I podemos observar que a quantidade de bens adquiridos por Lopo Fernandes é muito superior aos bens alienados. A geografia das alienações localizava-se na região de Alenquer. Estas foram efectuadas através de escambos que o senhor de Ferreira realizou com o mosteiro de Alcobaça ${ }^{48}$. Podemos apontar como causa provável o facto destes bens se localizarem longe do eixo de passagem e estadia da corte régia.

O mosteiro de Santa Cruz de Coimbra concedeu em préstamo a Lopo Fernandes e a sua mulher, em suas vidas, bens em Santarém e seu termo como

\footnotetext{
${ }^{45}$ R. C. Gomes, A corte dos reis (...), p.249.

${ }^{46}$ ADF, Caja 1, n. ${ }^{\circ} 1$ tranc. por A. Franco Silva, "Los Pacheco (...)”, p.977-979.

47 J. MAttoso, "O contraste entre a cidade e o campo", História de Portugal, dir. de J. H. SARAIVA, Lisboa, 1983, p.179 e 189.

${ }^{48}$ IAN/TT Mosteiro de Santa Maria de Alcobaça, 2ainc, m.11, n. ${ }^{2} 251$.
} 
reconhecimento de toda a ajuda que sempre fizeram ao dito mosteiro ${ }^{49}$ [Mapa I]. Porém, após a morte de Lopo Fernandes o cenóbio entra em litígio com D. Maria de Vilobos porque considera que este préstamo foi efectuado em seu prejuízo, sendo gravemente lesado porque Lopo Fernandes e D. Maria receberam durante muitos anos as rendas e pensões dos referidos bens que valiam mil libras em cada ano. $\mathrm{O}$ mosteiro pedia aos ouvidores e juízes régios que julgassem os ditos contratos de doação por nulos ${ }^{50}$. Assim localiza-se em Santarém e seus termos, por um lado, a maior mancha de bens detidos por Lopo Fernandes e, por outro, foi esta cidade local de paragem deste senhor, que variadas vezes estanciou nos paços que detinha na urbe escalabitana ${ }^{51}$. Maria Ângela Beirante refere que Santarém era local de residência de homens que exerciam cargos na corte ${ }^{52}$. Para a escolha desta região muito deve ter contribuído não só uma possível associação preferencial ao ambiente urbano, mas também duas qualidades naturais reunidas pela urbe escalabitana: por um lado, os solos férteis em seu redor e, por outro, as suas vias de comunicação, quer terrestres, quer fluviais que permitiam facilidades de deslocação ${ }^{53}$. Os bens urbanos localizavam-se, essencialmente, dentro das muralhas nos mais variados sítios, mas sempre em zonas de grande importância. Refiram-se, umas casas junto à Porta da Inveja ${ }^{54}$, (não será demais salientar que é pelas portas que a vila se encontra em contacto com o restante mundo, pois é, por estas que entram novas pessoas na cidade ou que dela saem). Mencionem-se outras casas na Alcáçova Velha ${ }^{55}$, onde se encontrava, até D. Afonso III (1248-1279), o Paço Real que, para além de residência dos monarcas, funcionava como centro da política e da administração do reino. No entanto, o Bolonhês mudou este paço para um outro local junto à porta de Leiria, denominado, por antonímia, de Alcáçova Nova. Apesar da Alcáçova Velha ter perdido, no século XIV, muita da sua vitalidade não deixa de ser o bastião do poder régio naquela cidade, assim como local de residência de muitos indivíduos pertencentes à nobreza, mas também o sítio onde

${ }^{49}$ IAN/TT, Mosteiro de Santa Cruz de Coimbra, 2a inc., m.17, n. ${ }^{\circ} 7$ e m.48, Alm.34, m.9, n. ${ }^{\circ} 16$.

${ }^{50}$ IAN/TT, Mosteiro de Santa Cruz de Coimbra, $2^{\mathrm{a}}$ inc., m.17, Alm.33, n. ${ }^{\circ} 15$, m.7.

${ }^{51}$ IAN/TT, Mosteiro de Santos o Novo, m.42, n. ${ }^{\circ} 861$; Mosteiro de Santa Cruz de Coimbra, $2^{\mathrm{a} i n c .}$, m.17, n. ${ }^{\circ} 10$.

${ }^{52}$ M. Â. BeIRANTE, Santarém medieval, Lisboa, 1980, p.198.

53 Sobre veja-se, M. Â. Beirante, Santarém (...); M. Viana, Os vinhedos medievais de Santarém, Cascais, 1998; IDEM, Espaço e povoamento numa vila portuguesa (Santarém, 11471350), Ponta Delgada, 2003 (dissertação de Doutoramento policopiada).

${ }^{54}$ IAN/TT, Mosteiro de Santa Cruz de Coimbra, $2^{\mathrm{a}}$ inc., m.17, Alm.33, n. ${ }^{\circ} 15$, m.7.

${ }^{55}$ IAN/TT, Mosteiro de Santa Cruz de Coimbra, 2a inc., m.17, n. ${ }^{\circ} 7$ e m.48, Alm.34, m.9, n. ${ }^{\circ} 16$. 
os mestres das ordens de Cristo e Avis possuíam os seus paços ${ }^{56}$. A posse deste tipo de bens no centro da urbe escalabitana vem demonstrar, uma vez mais, a estrita proximidade de Lopo Fernandes com o poder real e com a própria pessoa do rei [Quadro II].

Numa sociedade em que uma importante parte da riqueza reside ainda na propriedade do solo, encontramos em redor da cidade, no termo de Santarém ${ }^{57}$, esta nobreza de fidalgos próximos do monarca a deter outro tipo de bens. Assim, Lopo Fernandes detem desde olivais, a vinhas e herdades de pão ${ }^{58}$. Os campos férteis de Santarém são propícios à produção destes três elementos básicos da alimentação medieval: azeite, vinho e cereais. Ainda fora da malha urbana a atracção pelo rio essa via privilegiada de ligação a Lisboa - levou Lopo Fernandes a possuir casas na importante zona da Ribeira [Mapa I], mas também a deter bens de raiz na zona do Rego de Manços ${ }^{59}$, caracterizada por uma vasta e intensa policultura, responsável por um significativo abastecimento da cidade ${ }^{60}$.

No termo de Santarém Lopo Fernandes comprou bens na região de Tomar $^{61}$, que mais tarde veio a emprazar, talvez devido ao seu relativo afastamento da mancha principal das suas propriedades ${ }^{62}$. É nítido o objectivo de implantação na região de Santarém porque, além do mais, foi em Vale da Talha que usurpou herdades ao mosteiro de Santa Cruz de Coimbra ${ }^{63}$.

56 M. A. Beirante, Santarém (...), p.59-67; R. C. Gomes, A corte dos reis (...), p.262; J. MAtтoso, "Os nobres nas cidades portuguesas da Idade Média", Obras completas, vol. 8 - Portugal Medieval. Novas interpretações, Lisboa, 2002, pp.211-212.

57 “O termo é, para começar, suporte de uma comunidade humana, em cujo seio os homens circulavam e se fixam" (L. A. da FONSECA, "Lisboa medieval e o seu termo" Lisboa subterrânea, Raffaella d'Intino (coord.), Lisboa/Milão, 1994, p. 90).

${ }^{58}$ IAN/TT, Mosteiro de Santa Cruz de Coimbra, $2^{\mathrm{a}}$ inc., m.17, Alm.33, n. ${ }^{\circ} 15$, m.7.

59 "Este topónimo que, no seu sentido restrito, parece particularizar exclusivamente a depressão ou vale por detrás dos Paços do Bispo de Lisboa, num sentido mais lato, aplica-se a uma vasta zona (...) que engloba as Manteigas, Fontainhas, Valbom, Poços e Pé-de-Aranha, já perto de Santa Maria do Monte" (in M. A. BeIRANTE, Santarém (...), p.158).

${ }^{60}$ IAN/TT, Mosteiro de Santa Cruz de Coimbra, $2^{\mathrm{a}}$ inc., m.17, Alm.33, n. ${ }^{\circ} 15$, m.7; Mosteiro de Santa Cruz de Coimbra, $2^{\mathrm{a}}$ inc., m.17, n. ${ }^{\circ} 7$ e m.48, Alm.34, m.9, n. ${ }^{\circ} 16$.

${ }^{61}$ IAN/TT, Mosteiro de Santa Cruz de Coimbra, 2ainc, m.48, Alm.34, m.9, n. ${ }^{2} 28$.

${ }^{62}$ IAN/TT, Mosteiro de Santa Cruz de Coimbra, $2^{\mathrm{a}}$ inc, m.17, Pasta 9, n. ${ }^{\circ} 9$ e Alm.33, m.1, n. ${ }^{\circ} 1$. $^{2}$

${ }^{63}$ IAN/TT, Mosteiro Santa Cruz de Coimbra, 2ainc, m.48, Alm.34, m.9, n. ${ }^{030 .}$ 
Devido ao facto deste senhor ter desempenhado funções de serviço na corte e na própria na casa da rainha, terá acompanhado frequentemente os monarcas, passando, por isso, longas temporadas em Lisboa. Assim se entende melhor a pequena mancha de bens que também detinha nas localidades do termo olisiponense $\mathrm{e}^{64}$.

Durante a Idade Média era prática comum entre os nobres escolherem o espaço funerário. Lopo Fernandes escolheu como local para ser sepultado e perpetuar a sua memória a Sé Catedral de Lisboa, o mesmo escolhido pelo $\mathrm{Bravo}^{65}$. De referir, que o enterramento de D. Afonso IV e de D. Beatriz, sua mulher, na Sé de Lisboa constituiu uma excepção aos locais escolhidos tanto pelos seus antecessores como pelos seus sucessores ${ }^{66}$. Foi, assim, junto do monarca, que este "privado" régio pretendeu repousar eternamente. Julgamos que esta escolha não é desprovida de significado. Lopo Fernandes procurou, assim, manter post-mortem a sua proximidade face à pessoa que mais marcou o seu quotidiano; ao escolher sepultura no mesmo edifício da catedral de Lisboa, na capela de S. Cosme e S. Damião, mantinha, para a eternidade, a sua proximidade face a D. Afonso IV. O sarcófago com jazente de Lopo Fernandes [Figura I] foi produzido no atelier de escultores de Lisboa e, é considerado por Pedro Dias como a mais bela obra da Sé de Lisboa ${ }^{67}$.

${ }^{64}$ IAN/TT, Mosteiro de Santa Maria de Alcobaça, $2^{\mathrm{a}}$ inc., m.11, n. ${ }^{\circ} 25 ;$ Gav.21, m.10, n. ${ }^{\circ} 1$. O rei D. Pedro após o confisco dos bens que fez a Diogo Fernandes Pacheco, filho de Lopo Fernandes, apossou-se dos bens que este senhor possuía em Belas e mandou aí edificar os paços régios (R. C. GOMES, A corte dos reis (...), pp.267-268).

${ }^{65}$ A procura desta proximidade para além da morte foi já referida por B. V. e SousA, As relações entre Afonso IV de Portugal (...), p.8. Este mesmo edifícios foi, também, local de acolhimento dos túmulos e lápides sepulcrais de D. Grácia Fróis, mãe de D. Pedro Afonso, terceiro conde de Barcelos, de D. Maria de Vilalobos, segunda mulher de Lopo Fernandes Pacheco, de uma infanta portuguesa, de D. Margarida Albernaz, de uma dama desconhecida, de Bartolomeu Joanes, de bispos e elementos do cabido (C. V. Fernandes, Memórias de Pedra. Escultura tumular medieval da Sé de Lisboa, Lisboa, 2001, pp. 24-25).

${ }^{66}$ Todos os reis da primeira dinastia escolheram como lugar de sepultura um santuário da sua devoção pessoal: Afonso Henriques (1143-1185) e Sancho I (1185-1211) o mosteiro de Santa Cruz de Coimbra, para Afonso II (1211-1223), Afonso III e D. Pedro (1357-1367) a abadia de Alcobaça, para D. Dinis o mosteiro de Odivelas, para D. Fernando (1367-1383) os franciscanos de Santarém, para D. João I (1385-1433) os dominicanos de Santa Maria da Vitória. Porém, D. Afonso IV quebrou esta tradição colectiva de eleger um mosteiro ou um convento como local de sepultura "indicando assim que prefere uma vinculação por assim dizer institucional a uma autoridade religiosa que não representa Deus pelos mesmos critérios, mas pela legitimidade do poder sacramental" (J. MAtToso, “O poder e a morte", Poderes Invisíveis. O imaginário medieval, Lisboa, 2001, pp. 85-90.

${ }^{67}$ P. DIAS, "A escultura gótica. Primeiras manifestações em Portugal”, História da Arte em Portugal, vol. IV, Lisboa, 1986, p. 124. 
Neste encontram-se esculpidas de modo ostentatório a heráldica da sua linhagem ${ }^{68}$. Durante a Idade Média assiste-se a uma busca pelo não esquecimento da vida e dos feitos, sentimento que se materializava no avolumar, por um lado, de encomendas de túmulos e, por outro, com representações escultóricas dos defuntos, por vezes, acompanhados de elementos distintivos da sua individualidade. Assim, nesta capela encontra-se, ainda hoje, embutida na parede, coroando o monumento funerário, uma lápide na qual se registam os mais relevantes feitos desta importante personagem [Figura II $]^{69}$. A lápide encontra-se ladeada por duas bandas verticais

${ }^{68}$ Nestas linhas procuramos, somente, apresentar de forma muito sumária algumas considerações sobre o túmulo onde se encontra sepultado Lopo Fernandes. Para um conhecimento mais aprofundado vejam-se os estudos dos especialistas que se têm debruçado exaustivamente sobre este assunto, assim como, a bibliografia aí citada pelos vários autores: F. de SÃo LuIS, "Archeologia portugueza. A Sé de Lisboa. Memória do cónego Luís Duarte Vilella da Silva emendada e anotada por Sua Eminência o Cardeal Patriarca D. Francisco de S. Luíz", Revista Universal Lisbonense, XIII, 18, 1857; J. P. RIBEIRO, "Dissertação XV. Sobre a Paleografia de Portugal", Dissertações chronologicas e criticas ..., vol. IV, $2^{\text {a }}$ ed., Lisboa, 1867, pp. 81-236; G. PEREIRA, "Dois túmulos na sé de Lisboa", Arte portuguesa, Ano I, Lisboa, 1895, pp.14-16; G. de M. SEQueIRA, e N. de Brito, Sé de Lisboa. Estudo histórico-arqueológico e artístico, col. "Monumentos de Portugal", 8, Porto, 1930; J. CASTILHO, Lisboa Antiga. II ${ }^{\mathrm{a}}$ parte - Os bairros orientaes, vol. V, $2^{\mathrm{a}}$ ed., Lisboa 1934-1938; J. M. C. de SOUSA, Inscrições portuguesas de Lisboa (séculos XII a XIX), Lisboa, 1940; IDEM, Contribuições para uma ementa dos jacentes portugueses, Lisboa, 1946; IDEM, Os jacentes da Sé de Lisboa e a sua indumentária, Lisboa, 1951; IDEM, "A data da deposição do cadáver de Lopo Fernandes Pacheco no túmulo da Sé”, $O$ arqueólogo português, Nova série (2a), III, Lisboa, 1956, pp. 125-127; IDEM, Inscrições sepulcrais da Sé de Lisboa, $3^{\text {a }}$ ed., n. ${ }^{\circ} \mathrm{XV}$, Lisboa, 1982, pp. 9-41; R. dos SANTOS, $A$ escultura em Portugal, 3 vols., Lisboa, 1948; Documentos para a História da cidade de Lisboa. Cabido da Sé. Sumários de Lousada. Apontamentos dos brasões. Livro dos bens próprios do reis e rainhas, Lisboa, 1954; A. E. M. ZuQueTE (coord. de), Armorial Lusitano, Lisboa, 1961; A. B. Freire, Brasões da sala de Sintra, vol. I, $3^{\mathrm{a}}$ ed., Lisboa, 1973; V. Correia, Três túmulos, ${ }^{\mathrm{a}}$ ed., Obras, vol. V, Coimbra, 1978, pp. 105-232; L. G. de L. e TÁvorA, A heráldica medieval(...); P. DIAS, "A escultura gótica. (...)"; IDEM, "O gótico", História da Arte em Portugal, vol. 4, Lisboa, 1986; F. E. R. FerreIRA, "Busto do presumível canteiro do túmulo de Lopo Fernandes Pacheco", Olisipo. Boletim do grupo "Amigos de Lisboa", 2a série, 7, 1998; M. J. BARroCA, Aux confins du Moyen Age, Catálogo da Exposição, Europália-91, Gand, 1991; IDEM, Pera Guerreiar. Armamento medieval no espaço português, (Catálogo de Exposição), Palmela, 2000; IDEM, Epigrafia medieval portuguesa (862-1422), Lisboa, 2000; C. V. FERNANDES, Memórias de Pedra (...).

69 “+: AQ(u)I : IAZ : LOPO : FERNAnDEZ : PACHECO : SENHOR : DE / : FER(r)EIRA : E : MOORDOMO : MOOR : DOMI(n)FANTe : DO / : MPEDRO : E CHANCELER : DA : REINHA : DONAMBEATR / IZ : O QUAL : FOIMMERCEE : E : FEITURA : DELREI : DOM : AFO / NSO : O QUARTO : E : FOI : CoN EL : NA : LIDE : Que : (h)OUVE : Com : ELREI : D / EM GRA(n)ADA : HU : ESTE : REI : FOI : FAZER : AIUDA : A : ELREI :/DOM : AFONSO : DE : CASTELA : QUANDO : ELREI : DE : BENAMA /RIN : IAZIA : SOBRE : TARIFA : NA : ERA : DE : MIL : E : $\mathrm{C}^{\mathrm{a}} \mathrm{C}^{\mathrm{a}} \mathrm{C}^{\mathrm{a}}: \mathrm{E}: / \mathrm{L}^{\mathrm{a}} \mathrm{X}^{\mathrm{a}} \mathrm{X}^{\mathrm{a}}: \mathrm{E}$ : VIII : ANOS : AO : Qual : LOPO : FERNAnDEZ : FOI : EN / AVINHON : : DADA : COn : GRAnDE : HOnRA : PeLO : PAPA : BE / NEDITO : HUmA : ROSA : DOURO : QUE : ELE : CON : GRAnDE : / HONRA : POS : EN : ESTA : SEE : TANTO : 
onde se esculpiram, em cada lado, dois brasões de espigão, suspensos por cadeados de pregos, onde se podem divisar as Armas dos Pachecos: uma caldeira veirada com asa rematada em cabeça de serpente [Figura III]. Durante a Idade Média a Capela de S. Cosme e de S. Damião era encerrada por uma grade de ferro forjado ${ }^{70}$ talvez para proteger a referida rosa de ouro, oferta do Papa a Lopo Fernandes, colocada no Altar desta Capela da charola da Sé.

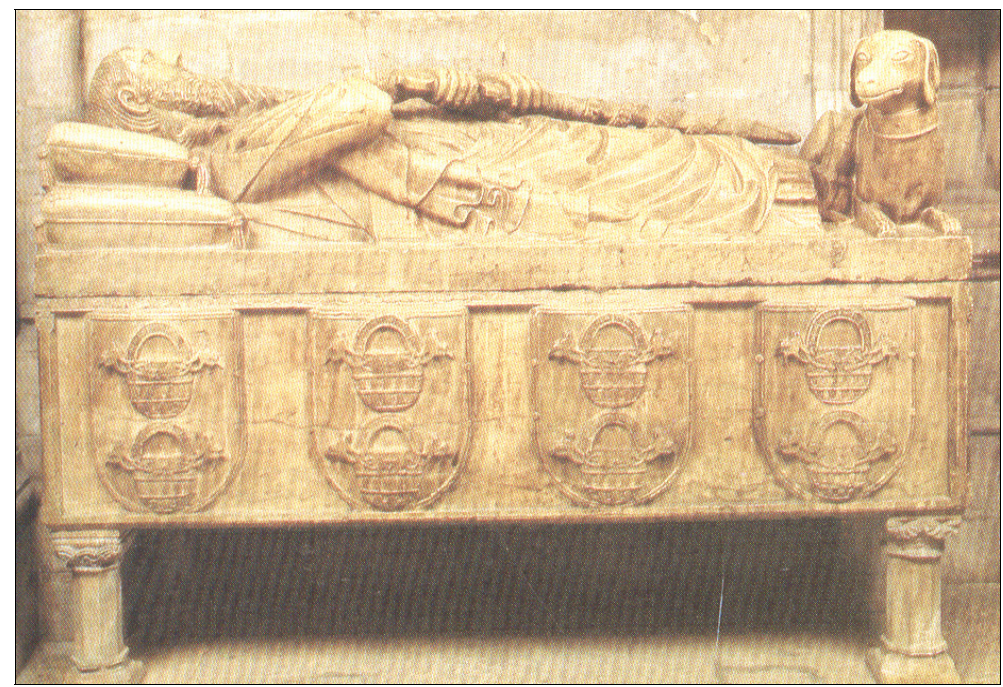

Figura I - Túmulo de Lopo Fernandes Pacheco. Século XIV. Capela de S. Cosme e S. Damião. (in Memória de Portugal. O milénio português, coord. geral R. CARNEIRO, e coord. científica A. T. de MATOS, Lisboa, 2001, p. 175)

Que : DALO : CHEGO / U : O QUAL : FOI : CASADO : CON : DONA : MARIA : FILHA / DE : DOM : RUI : GIL : DE : VILA : LOBOS : E : DE : DON /A : TAREIIA : SANCHEZ : Que : FOI : FILHA : DELREI : / DOM : SANCHO : DE : CASTELA : E FOI : EN : TERRA / DO : EN : ESTE : MOIIMENTO : XX : E : NOVE : DIAS : / DE : DEZENBRO : DA : ERA : DE : MIL : $\mathrm{C}^{\mathrm{a}} \mathrm{C}^{\mathrm{a}} \mathrm{C}^{\mathrm{a}}: \mathrm{E}$ : LXXX : / E : SETE : ANOS M(transcrito em M. BARROCA, Epigrafia medieval (...), vol. 2/T. II, p. 1699).

${ }^{70}$ Esta grade foi originalmente dourada, subsistindo ainda vestígios desse acabamento (veja-se M. BARroca, Epigrafia medieval (...), p. 1706, assim como, a bibliografia aí citada. 


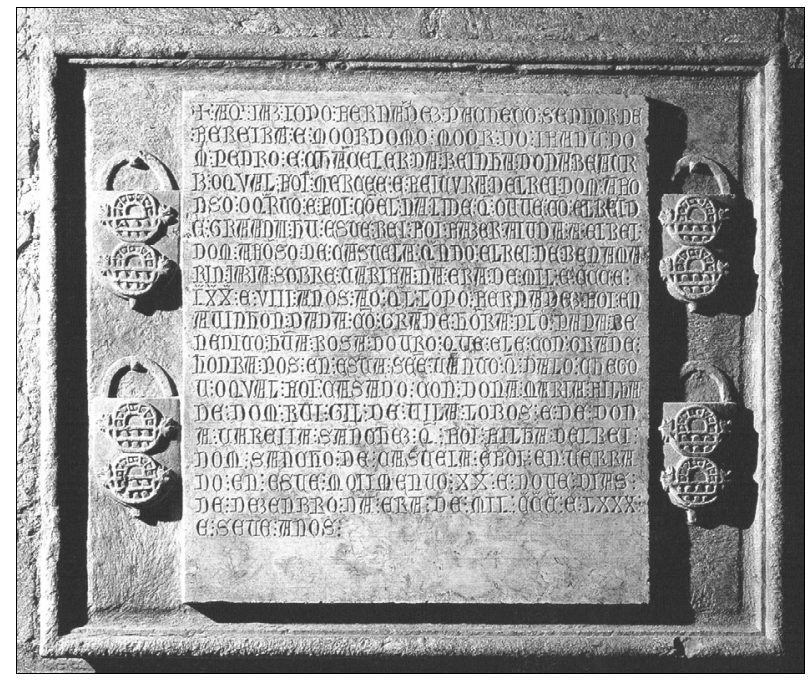

Figura II - Epitáfio funerário de Lopo Fernandes Pacheco. Século XIV. Capela de S. Cosme e S. Damião. (in C. V. Fernandes, Memórias de Pedra. Escultura tumular medieval da Sé de Lisboa, Lisboa, 2001, p. 44. trancrição na nota supra $n^{\circ} 69$ ).

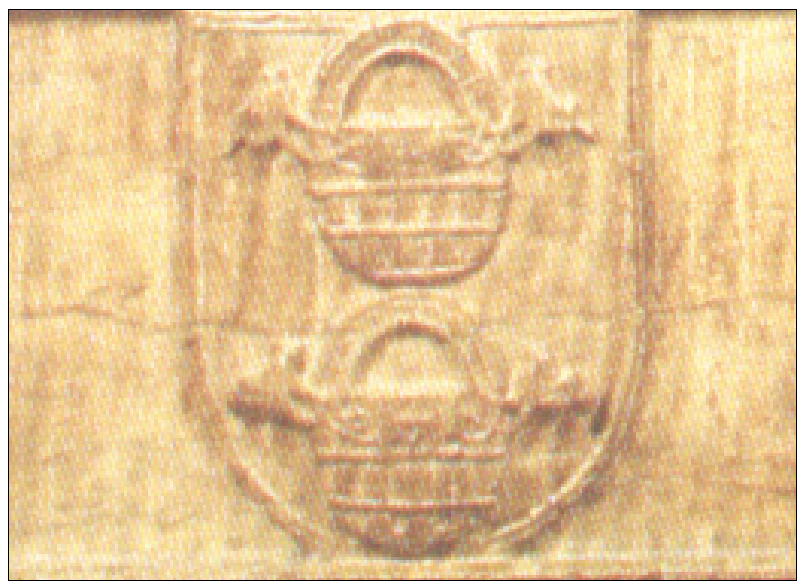

Figura III - Promenor das armas dos Pachecos (in Memória de Portugal..., p.175) 
A trajectória de Lopo Fernandes Pacheco permite-nos percepcionar como através dos estreitos laços de vassalidade com o monarca um membro da pequena nobreza local ascende na hierarquia nobiliárquica tornando-se, deste modo, no fidalgo português mais importante da sua época, fazendo ressaltar a respectiva linhagem, que assim se vê alcandorada a uma posição de superioridade face às restantes. De facto, a aproximação à corte e a privança com a própria pessoa do rei, assim como a protecção real foram, particularmente, propícias para a ascensão de Lopo Fernandes. Para além, da sua indubitável força política é, também notória a sua considerável base patrimonial, revelando-se um administrador atento e cuidadoso dos seus bens. Assim, para além, de um património extenso, este senhor alcançou uma posição privilegiada na rede do poder central, a qual procurou, incessantemente, consolidar. Este é um bom exemplo de que certos êxitos individuais marcam a trajectória de uma linhagem. Trajectória essa que seria interrompida por seu filho, Diogo Lopes Pacheco, um dos assassinos de Inês de Castro.

\begin{tabular}{|c|c|c|}
\hline & & \\
\hline Camareiro & Gil Martins & $\begin{array}{l}\text { IAN/TT, Mosteiro de Santa Cruz de Coimbra, } 2^{\mathrm{a}} \text { inc, m.17; Pasta } \\
9, \text { n. }^{\circ} 9 \text {; e Alm.33, m.1, n. }{ }^{\circ} 1\end{array}$ \\
\hline \multirow{4}{*}{ Clérigo } & $\begin{array}{l}\text { Estevão Gomes, prior de } \\
\text { la Mota }\end{array}$ & IAN/TT, Gav.18, m.5, n. ${ }^{\circ} 32 ;$ G.T.T., vol.8, p.566-575 \\
\hline & $\begin{array}{l}\text { João Eanes } \\
\text { João Romeu }\end{array}$ & \multirow{3}{*}{$\begin{array}{l}\text { IAN/TT, Mosteiro de Santos o Novo, m. } 77, \text { n. }{ }^{\circ} 1542 \\
\text { IAN/TT, Mosteiro de Santa Cruz de Coimbra, } 2^{\text {a }} \text { inc, m. } 17, \text { n. }{ }^{0} 7 \text {, } \\
\text { m. } 48, \text { Alm.34, m.9, n. }{ }^{\circ} 6 \text {; Mosteiro de Santos o Novo, m.42, } \\
\text { n. } 861, \text { m. } 77, \text { n. }{ }^{\circ} 1542\end{array}$} \\
\hline & Pedro Martins & \\
\hline & Vicente Gonçalves & \\
\hline Corretor & João Afonso & $\begin{array}{l}\text { IAN/TT, OC, Mosteiro de Santa Maria de Lorvão, g.6, m.1, } \\
\text { n. }{ }^{\circ} 12 / 1\end{array}$ \\
\hline Escrivão & Estevão Eanes & $\begin{array}{l}\text { IAN/TT, Mosteiro de Santa Cruz de Coimbra, } 2^{\mathrm{a}} \text { inc, m. } 17 \text {, Pasta } \\
9, \mathrm{n}^{\circ} 9 \text { e Alm.33, m. } 1, \mathrm{n} .{ }^{\circ} 1\end{array}$ \\
\hline \multirow{3}{*}{ Escudeiro } & Aires Peres de Minho & $\begin{array}{l}\text { IAN/TT, OC, Mosteiro de Santa Maria de Lorvão, g.5, m.5, } \\
\text { n. }{ }^{\circ} 12 / 1\end{array}$ \\
\hline & João Eanes & IAN/TT, Mosteiro de Santos o Novo, m.42, n. ${ }^{\circ} 861$ \\
\hline & Rui Vicente & IAN/TT, Mosteiro de Chelas, m.36, n. ${ }^{\circ} 702$ \\
\hline \multirow[b]{2}{*}{ Homem } & Pedro de Lisboa & IAN/TT, Mosteiro de Santos o Novo, m.77, n. ${ }^{\circ} 1542$ \\
\hline & Tomé Lopes & $\begin{array}{l}\text { IAN/TT, Mosteiro de Santa Cruz de Coimbra, } 2^{\mathrm{a}} \text { inc, m. } 17 \text { e Pasta } \\
9, \text { n. }^{\circ} 9 \text { e Alm. } 33, \text { m. } 1, \text { n. }^{\circ} 1\end{array}$ \\
\hline Ouvidor & Vicente Anes & $\begin{array}{l}\text { IAN/TT, Mosteiro de Santa Cruz de Coimbra, } 2^{\mathrm{a}} \text { inc, } \mathrm{m} .48 \text {, } \\
\text { Alm. } 34, \text { m.9, n. }{ }^{\circ} 27\end{array}$ \\
\hline \multirow[t]{5}{*}{ Procurador } & Afonso Domingues & $\begin{array}{l}\text { IAN/TT, Mosteiro de Santa Maria de Alcobaça, } 1^{\text {a }} \text { inc., Docs. } \\
\text { Part., m. } 31, \text { n. }^{2} \text {. }\end{array}$ \\
\hline & $\begin{array}{l}\text { Afonso Esteves, que } \\
\text { mora em Tomar }\end{array}$ & $\begin{array}{l}\text { IAN/TT, Mosteiro de Santa Cruz de Coimbra, } 2^{\mathrm{a}}{ }^{\mathrm{innc}} \mathrm{m} .17 \text {, } \\
\text { Alm. } 33, \mathrm{~m} .1, \mathrm{n}^{\circ} 1 \text {, Pasta } 9, \mathrm{n}^{\circ}{ }^{\circ}\end{array}$ \\
\hline & João Eugres & IAN/TT, OC, Mosteiro de Santa Maria de Lorvão, g.6, m.3, n. ${ }^{0} 7 / 2$ \\
\hline & Martim Lourenço & IAN/TT, Mosteiro de Santa Cruz de Coimbra, $2^{\mathrm{a}}$ inc, m.17, n. ${ }^{\circ} 10$ \\
\hline & Pedro Domingues Algoz & $\begin{array}{l}\text { IAN/TT, Mosteiro de Santa Maria de Alcobaça, } 2^{\text {a }} \text { inc., m.11, } \\
\text { n. }{ }^{\circ} 251\end{array}$ \\
\hline
\end{tabular}




\begin{tabular}{lll}
\hline & Pedro de Lisboa & IAN/TT, Mosteiro de Santos o Novo, m.77, n. ${ }^{\circ} 1542$ \\
\hline \multirow{2}{*}{ Vassalo } & Martim Lourenço & IAN/TT, Mosteiro de Santa Cruz de Coimbra, ${ }^{\text {a }}$ inc, m.17, n. ${ }^{\circ} 10$ \\
\cline { 2 - 3 } & Rui Vicente & IAN/TT, Mosteiro de Chelas, m.36, n. ${ }^{\circ} 702$ \\
\hline
\end{tabular}

Quadro II - Bens detidos por Lopo Fernandes Pacheco

\begin{tabular}{|c|c|c|c|c|}
\hline Data & Tipo De Bens & Localização & $\begin{array}{l}\text { Formas de } \\
\text { Aquisição / } \\
\text { Alienação }\end{array}$ & Fontes \\
\hline \multirow[b]{2}{*}{ ? } & Vinha & termo de Alenquer & \multirow[b]{2}{*}{ Dá em escambo } & \multirow{2}{*}{$\begin{array}{l}\text { IAN/TT, Mosteiro de } \\
\text { Santa Maria de Alcobaça, } \\
2^{\text {a } i n c, ~ m .11, ~ n . ~}{ }^{\circ} 251\end{array}$} \\
\hline & uma horta & Alenquer & & \\
\hline \multirow{3}{*}{$?$} & $\begin{array}{l}\text { Parte e o direito do } \\
\text { casal }\end{array}$ & Pedra Longa, em Belas & \multirow{3}{*}{$\begin{array}{l}\text { Recebe em } \\
\text { escambo }\end{array}$} & \multirow{3}{*}{ 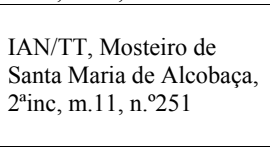 } \\
\hline & Casal & Idanha, Belas, Sintra & & \\
\hline & $\begin{array}{l}\text { Parte e direito que há } \\
\text { no casal }\end{array}$ & $\begin{array}{l}\text { Ventoso, Belas. Termo de } \\
\text { Lisboa }\end{array}$ & & \\
\hline $1328-05-15$ & Herdade e vinhas & termo de Lisboa & Dá em escambo & $\begin{array}{l}\text { IAN/TT, Gav.21, m.10, } \\
\text { n. }{ }^{\circ} 1\end{array}$ \\
\hline $1328-05-15$ & Uma quintã e casais & Belas, Sintra & $\begin{array}{l}\text { Recebe em } \\
\text { escambo }\end{array}$ & $\begin{array}{l}\text { IAN/TT, Gav.21, m.10, } \\
\text { n. }{ }^{\circ} 1\end{array}$ \\
\hline $1330-08-29$ & Morgado & Ferreira de Aves, Satão & Doação régia & $\begin{array}{l}\text { ADF, Caja 1, n. }{ }^{\circ} 1 \text {, pp. } 980- \\
981 \text { (trans. P. A. Franco } \\
\text { Silva, Los Pacheco, p.977- } \\
\text { 979) }\end{array}$ \\
\hline $1332-02-24$ & Quintã & $\begin{array}{l}\text { Duas Igrejas, Ferreira de Aves, } \\
\text { Sátão }\end{array}$ & Compra & $\begin{array}{l}\text { IAN/TT, OSB, Mosteiro } \\
\text { de Santa Eufémia de } \\
\text { Ferreira de Aves, m.1, } \\
\text { n. }{ }^{33}\end{array}$ \\
\hline $1334-08-27$ & Quintã & $\begin{array}{l}\text { Margem de Arada, termo de } \\
\text { Alenquer }\end{array}$ & Compra & $\begin{array}{l}\text { IAN/TT, Mosteiro de } \\
\text { Santos o Novo de Lisboa, } \\
\text { m. } 77, \text { n. } 1542\end{array}$ \\
\hline \multirow[t]{17}{*}{$1365-04-03$} & um chão & aquém do Ribeiro de Manços & \multirow{17}{*}{$\begin{array}{l}\text { Recebe em } \\
\text { préstamo }\end{array}$} & \multirow{12}{*}{$\begin{array}{l}\text { TT, Mosteiro de Santa } \\
\text { Cruz de Coimbra, } 2^{\mathrm{a}} \text { inc, } \\
\text { m.17, Alm. } 33, \text { n. }^{0} 15, \mathrm{~m} .7\end{array}$} \\
\hline & um herdamento & Manteigas & & \\
\hline & casas & $\begin{array}{l}\text { A par da Porta da Inveja, } \\
\text { Santarém }\end{array}$ & & \\
\hline & Casas & $\begin{array}{l}\text { Beco na Atafona, S. Nicolau, } \\
\text { Santarém }\end{array}$ & & \\
\hline & Casas & $\begin{array}{l}\text { Quintal das Donas, S. Nicolau, } \\
\text { Santarém }\end{array}$ & & \\
\hline & Casas & $\begin{array}{l}\text { Rua da Triparia na Ribeira, } \\
\text { Santarém }\end{array}$ & & \\
\hline & Casas & A par da Rua da Triparia & & \\
\hline & ? & $\begin{array}{l}\text { Malaqueijo, S. João da Ribeira, } \\
\text { Rio Maior }\end{array}$ & & \\
\hline & 6 casais & Calhariz, Azambuja, Rio Maior & & \\
\hline & 18 hastis de herdade & $\begin{array}{l}\text { a par de Santa Maria de } \\
\text { Valada, N. Sra da Expectação, } \\
\text { Cartaxo }\end{array}$ & & \\
\hline & 10 hastis de herdade & Capa Rota, Achete, Santarém & & \\
\hline & 18 hastis de herdade & jazem a par Muje & & \\
\hline & 18 hastis de herdade & Moncam & & \\
\hline & Olival & $\begin{array}{l}\text { A par dos paços do bispo de } \\
\text { Lisboa, Santarém }\end{array}$ & & \\
\hline & 1 monte & $\begin{array}{l}\text { Vale Covo, Mouriscas, } \\
\text { Abrantes e a Gesteira }\end{array}$ & & \\
\hline & 1 monte & Vale das Pegas & & \\
\hline & 1 monte & $\begin{array}{l}\text { Vale de Ossos, S. Salvador, } \\
\text { Santarém }\end{array}$ & & \\
\hline
\end{tabular}


Lopo Fernandes Pacheco: um valido de D. Afonso IV

\begin{tabular}{|c|c|c|c|c|}
\hline & & Santarém & & \\
\hline & $?$ & Ribeira de Calhariz & & \\
\hline \multirow{17}{*}{ 1335-06-09 } & Herdamento & Pereira, Chouto, Chamusca & \multirow{17}{*}{$\begin{array}{l}\text { Recebe em } \\
\text { préstamo }\end{array}$} & \multirow{17}{*}{$\begin{array}{l}\text { IAN/TT, Mosteiro de } \\
\text { Santa Cruz de Coimbra, } \\
2^{\mathrm{a}} \text { inc, m. } 17, \mathrm{n} .{ }^{\circ} 7 ; \mathrm{m} .48 \text {, } \\
\text { Alm. } 34, \mathrm{~m} .9, \mathrm{n} .{ }^{\circ} 16\end{array}$} \\
\hline & Herdamento & Moncam, termo de Santarém & & \\
\hline & Olival e pardo & $\begin{array}{l}\text { Além do rego de Manços, } \\
\text { termo e Santarém }\end{array}$ & & \\
\hline & Herdamento & $\begin{array}{l}\text { Montijos. Parte com } \\
\text { Alpiarcinho }\end{array}$ & & \\
\hline & Herdamento & Montijos & & \\
\hline & $\begin{array}{l}\text { Quintã, com suas } \\
\text { casas, vinhas, hortas, } \\
\text { campos }\end{array}$ & Almonda & & \\
\hline & 35 hastis de herdade & Toxe, no lugar de Requeixado & & \\
\hline & $\begin{array}{l}\text { Herdamentos, com sua } \\
\text { vinha, casas e suas } \\
\text { pertenças }\end{array}$ & Esparagal & & \\
\hline & $\begin{array}{l}\text { Vinhas com a herdade } \\
\text { toda }\end{array}$ & $\begin{array}{l}\text { Valada, N. Sra da Expectação, } \\
\text { Cartaxo }\end{array}$ & & \\
\hline & Casal & $\begin{array}{l}\text { Mata, S. Vicente do Paul, } \\
\text { Santarém }\end{array}$ & & \\
\hline & Lezíria & Do Tejo & & \\
\hline & $\begin{array}{l}\text { Olivais, vinhas e } \\
\text { herdades }\end{array}$ & Manteigas & & \\
\hline & O lugar que & & & \\
\hline & Casas & R. de S. Domingos, Santarém & & \\
\hline & $\begin{array}{l}\text { Casa, com seus terreos } \\
\text { e pertenças }\end{array}$ & Alcáçova Velha, Santarém & & \\
\hline & Casa & Cruz de S. Nicolau, Santarém & & \\
\hline & $\begin{array}{l}300 \text { libras em cada } \\
\text { ano }\end{array}$ & $\begin{array}{l}\text { pelos bens que nós havemos } \\
\text { em Torres Vedras e seus } \\
\text { termos }\end{array}$ & & \\
\hline $1336-05-02$ & 5 courelas de vinhas & A par da ribeira de Odivelas & Compra & $\begin{array}{l}\text { IAN/TT, Mosteiro de } \\
\text { Chelas, m.41, n. }{ }^{\circ} 914\end{array}$ \\
\hline \multirow{5}{*}{ 1334-09-06 } & Quintã & $\begin{array}{l}\text { margem de Arada, termo de } \\
\text { Alenquer }\end{array}$ & \multirow{5}{*}{ Dá em escambo } & \multirow{5}{*}{$\begin{array}{l}\text { IAN/TT, Mosteiro de } \\
\text { Santos o Novo de Lisboa, } \\
\text { m. } 77 \text {, n. } .^{\circ} 1542\end{array}$} \\
\hline & 2 casas de herdade & $\begin{array}{l}\text { margem de Arada, termo de } \\
\text { Alenquer }\end{array}$ & & \\
\hline & $\begin{array}{l}\text { uma grande seara de } \\
\text { vinha e pomar e } \\
\text { almoinha }\end{array}$ & $\begin{array}{l}\text { margem de Arada, termo de } \\
\text { Alenquer }\end{array}$ & & \\
\hline & 5 courelas de vinhas & 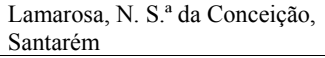 & & \\
\hline & duas courelas de vinha & $\begin{array}{l}\text { Vale do Homem, Meca, } \\
\text { Alenquer }\end{array}$ & & \\
\hline 1334-09-06 & Quintã & Belas, termo de Lisboa & $\begin{array}{l}\text { Recebe em } \\
\text { escambo }\end{array}$ & $\begin{array}{l}\text { IAN/TT, Mosteiro de } \\
\text { Santos o Novo de Lisboa, } \\
\text { m. } 77, \text { n. }^{\circ} 1542\end{array}$ \\
\hline \multirow{3}{*}{$1345-01-01$} & Quintã das lezírias & $\begin{array}{l}\text { Almourol, Tancos, Vila Nova } \\
\text { da Barquinha }\end{array}$ & \multirow{3}{*}{ Compra } & \multirow{3}{*}{ 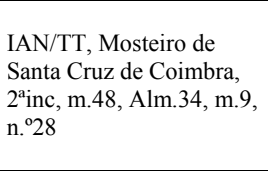 } \\
\hline & Casais & Giesteira, Martinxel, Abrantes & & \\
\hline & $\begin{array}{l}\text { Herdades, vinhas, } \\
\text { casas fontes, rossios, } \\
\text { árvores }\end{array}$ & Soianda, Casais, Tomar & & \\
\hline \multirow[b]{2}{*}{$1345-01-02$} & Bens & Tomar & \multirow[b]{2}{*}{$?$} & IAN/TT, Mosteiro de \\
\hline & Quintã das lezirias & Termo de Santarém & & $\begin{array}{l}2^{\text {a inc, }} \text { m.17; Pasta } 9, \text { n. }^{\circ} 9 ; \\
\text { e Alm.33, m.1, n. }{ }^{\circ} 1\end{array}$ \\
\hline \multirow{3}{*}{$1345-01-23$} & Casais & Giesteira, Martinxel, Abrantes & \multirow{3}{*}{ Empraza } & \multirow{3}{*}{$\begin{array}{l}\text { IAN/TT, Mosteiro de } \\
\text { Santa Cruz de Coimbra, } \\
2^{\text {a } i n c, ~ m .17, ~ P a s t a ~} 9, \text { n. }^{\circ} 9 \text { e } \\
\text { Alm. } 33, \text { m. } 1, \text { n. }^{\circ} 1\end{array}$} \\
\hline & Casais & Soianda, casais, Tomar & & \\
\hline & Bens e heranças & $\begin{array}{l}\text { Atalaia, N. Sr }{ }^{\mathrm{a}} \text { da Assunção, } \\
\text { Vila Nova da Barquinha }\end{array}$ & & \\
\hline 1349-03-11 & Herdade & Pias [Santarém] & Dá em doação & TT, Mosteiro de Santa \\
\hline
\end{tabular}


Vanda Lourenço

\begin{tabular}{|c|c|c|c|c|}
\hline & & & & $\begin{array}{l}\text { Cruz de Coimbra, } 2^{\mathrm{a}} \text { inc, } \\
\mathrm{m} .17, \mathrm{n}^{\circ} 10\end{array}$ \\
\hline $1355-05-27$ & Herdades & $\begin{array}{l}\text { Vale da Talha, termo de } \\
\text { Santarém }\end{array}$ & Usurpação & $\begin{array}{l}\text { IAN/TT, Mosteiro Santa } \\
\text { Cruz de Coimbra, 2ainc, } \\
\text { m. } 48 \text {, Alm. } 34, \text { m. } 9, \text { n. }{ }^{\circ} 30\end{array}$ \\
\hline $1355-06-28$ & $\begin{array}{l}\text { Quarta parte de dois } \\
\text { moinhos }\end{array}$ & Água de Abucela & Empraza & $\begin{array}{l}\text { ADF, Caja 1, n. }{ }^{2} 2 \text { (trans. } \\
\text { P. A. Franco Silva, Los } \\
\text { Pacheco, p.980-981) }\end{array}$ \\
\hline
\end{tabular}


Mapa I - Bens detidos por Lopo Fernandes Pacheco

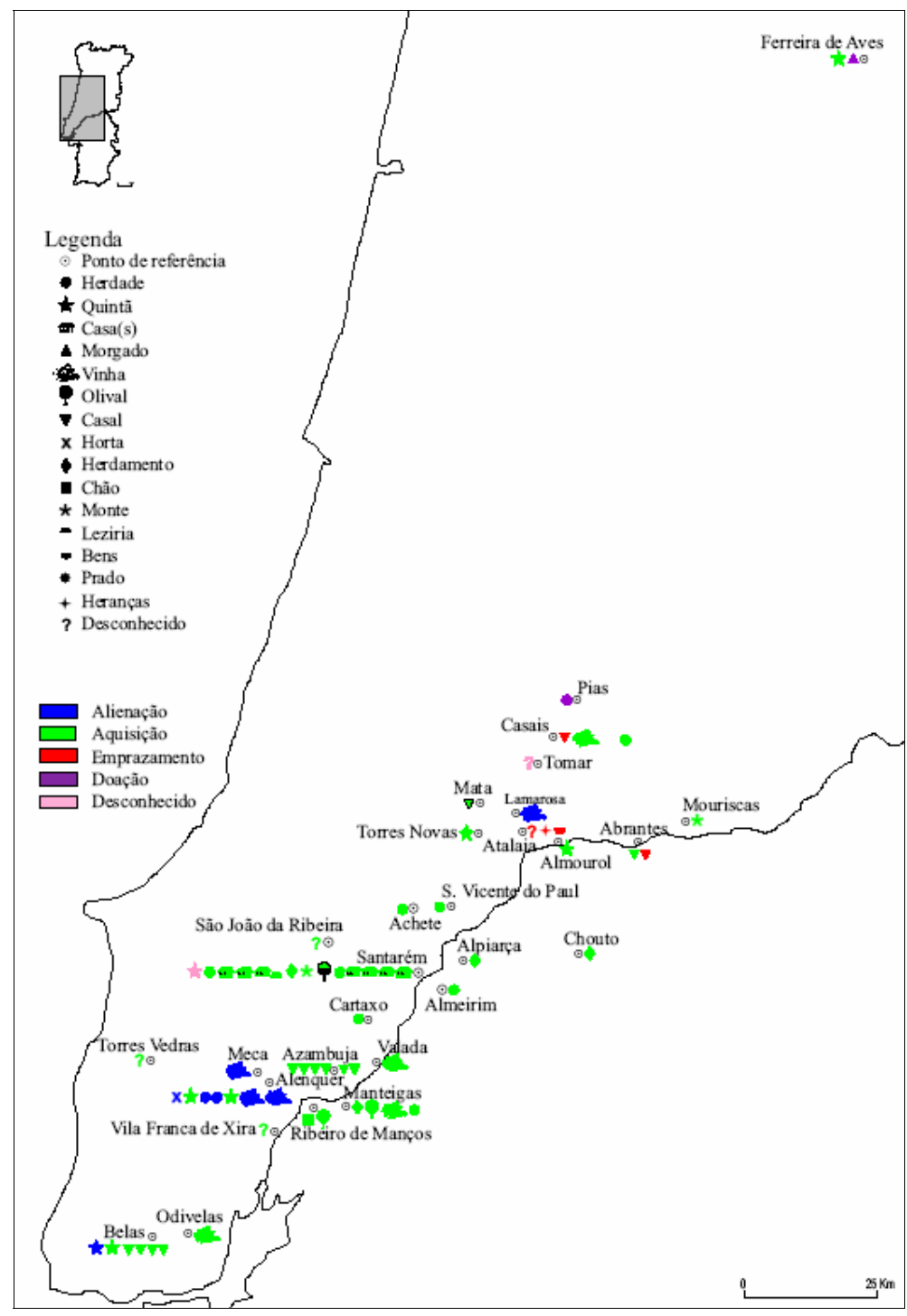


